\title{
Nitration of Benzene Using Mixed Oxide Catalysts
}

\author{
Vinod Mane $^{1}$, Mahind Lalaso ${ }^{1}$, Shobha Waghmode ${ }^{2}$, K. D. Jadhav ${ }^{1}$, \\ M. K. Dongare ${ }^{3}$, Sharda P. Dagade ${ }^{1 *}$ \\ ${ }^{1}$ Yashwantrao Mohite College, Bharati Vidyapeeth Deemed University, Pune 411038, India \\ ${ }^{2}$ Abasaheb Garware College, Pune, India \\ ${ }^{3}$ Catalysis Division, National Chemical Laboratory, Pune 411008, India
}

\begin{abstract}
Vapor phase nitration of benzene has been carried out, using dilute nitric acid as the nitrating agent, over $\mathrm{Fe} / \mathrm{Mo} / \mathrm{SiO}_{2}$ solid acid catalyst with more than $80 \%$ benzene conversion and $99 \%$ selectivity for mononitrobenzene. A series of $\mathrm{Fe} / \mathrm{Mo} / \mathrm{SiO}_{2}$ catalysts with various compositions were prepared using a sol-gel technique and characterized using X-ray diffraction analysis (XRD), BET specific surface area analysis, temperature-programmed desorption (TPD) of ammonia, and FTIR spectroscopic analysis of adsorbed pyridine. The results are correlated with structure and acidity of the catalysts.
\end{abstract}

Keywords: Benzene nitration, mixed oxides, Selectivity, Sol gel, Vapor phase,

\section{Introduction}

Nitrobenzene is one of the important aromatic nitro compound used as a solvent and as an intermediate for the manufacture of variety of organic compounds. Most nitrobenzene produced is converted to aniline, which has many downstream products. The nitration of benzene for commercial production of nitrobenzene (NB) is a well-established process, which has been used since about 1860[1]. In the basic process a mixture of nitric and sulfuric acid is used as nitrating agent and strongly exothermic reaction is conducted in batch- or continuous reactors. Typically the nitrating agent is a mixture of 56-60 \% (w/w) $\mathrm{H}_{2} \mathrm{SO}_{4}, 27-32 \%(\mathrm{w} / \mathrm{w}) \mathrm{HNO}_{3}$, and $8-17 \%(\mathrm{w} / \mathrm{w}) \mathrm{H}_{2} \mathrm{O}$ at a reaction temperature of $50-90^{\circ} \mathrm{C}$. The reaction mixture forms two phases and the rate of reaction is accordingly dependant on the kinetics and on the mixing efficiency. Sulfuric acid is gradually deactivated by water generated during the reaction and has to be replaced after deactivation.

Other conventional methods with several variations have also been proposed to produce mononitration of benzene. Single-phase nitration of benzene is carried out with a 2 -4-fold excess of $98 \%$ nitric acid at a reaction temperature of $20-60^{\circ} \mathrm{C}$ and ambient pressure and total conversion is claimed to be high [2]. Other azeotropic nitration of benzene conducted at $120^{\circ} \mathrm{C}-160^{\circ} \mathrm{C}$ with excess amount of benzene. Water generated during the reaction is removed as a water-benzene azeotrope and may be separated from the benzene, which is recycled to the reactor.

Vapor phase nitration of benzene to nitrobenzene over solid acid catalysts is expected to be a clean process without sulfuric acid waste, in contrast to the conventional liquid phase process which uses a mixed acid (concentrated nitric and sulfuric acid) as a nitrating agent and is accompanied with a large amount of dilute sulfuric acid waste. Many efforts devoted to developing a vapor phase process have been unsuccessful, because either the activity or life of catalysts was not satisfactory [3].

R. Prins et al.[4,5] have reported modified H-Y zeolite and a modified mordenite catalysts for the vapor phase nitration of benzene by dilute nitric acid. The modified mordenite kept high yield of nitrobenzene at a high space time yields.

Brei and coworkers [6] have reported the gas-phase nitration of benzene with $70 \% \mathrm{HNO}_{3}$ catalytic by superacid $\mathrm{WO}_{3} / \mathrm{ZrO}_{2}$ catalyst at $170^{\circ} \mathrm{C}$ under atmospheric pressure, with the yield of nitrobenzene in the range of $65-80 \%$ and $99 \%$ selectivity for mononitrobenzene. Although these solid acid catalysts showed good catalytic properties in nitration reaction, the recycling results of these catalysts were not referred, [7-10] which are important evaluation criterions for an excellent catalyst applied in industrial application.

Sato et al.[11-12] studied the vapor phase nitration of benzene over solid acid catalysts such as montmorillonite ion-exchanged with a multivalent metal ion, mixed oxides (e.g., $\mathrm{TiO}_{2}-\mathrm{MoO}_{3}$ ), the same oxides treated with sulfuric acid at $500^{\circ} \mathrm{C}$ and heteropolyacids partially neutralized. Although supported sulfuric acid showed good results for the vapor phase nitration of benzene.

Gong Shu-wen et al. [13] reported that silica supported $\mathrm{Cs}_{2.5} \mathrm{H}_{0.5} \mathrm{PMo}_{12} \mathrm{O}_{40}$ catalyst was prepared through sol-gel method with ethyl silicate-40 as silicon resource. The catalytic performance of the catalysts for benzene liquid-phase nitration was examined with $65 \%$ nitric acid as nitrating agent with high conversion $(95 \%)$ in optimized conditions.

Jin S. Yoo et al. [14] reported the metal oxides as catalysts for hydroxylation of benzene to phenol using nitric acid. $\mathrm{Fe} / \mathrm{Mo} / \mathrm{SiO}_{2}$ catalyst showed good activity for hydroxylation of benzene to phenol via gas 
phase nitric acid oxidation because of its dual functions: Nitrobenzene was selectively formed below $370^{\circ} \mathrm{C}$ and selective phenol formation above $400^{\circ} \mathrm{C}$.

Considering the potential of $\mathrm{Fe} / \mathrm{Mo} / \mathrm{SiO}_{2}$ catalyst for vapor phase nitration of benzene, we investigated this catalyst in detail for its activity for nitration of benzene. The advantage of using vapor phase conditions is the continuous thermal removal of water and the simple implementation of a continuous nitration process based on a downflow fixed-bed of the solid acid. Elevated reaction temperatures, however, lead to problems of safety, catalyst stability, by-product formation, and therefore the optimization of the reaction parameters is highly desired.

\section{1 Catalyst Preparation}

\section{Experimental}

\section{2. $1.1 \mathrm{Fe} / \mathrm{Mo} / \mathrm{SiO}_{2}$ :}

$\mathrm{Fe} / \mathrm{Mo} / \mathrm{SiO}_{2}$ catalyst was prepared by sol-gel process to obtain the catalyst with high surface area as well as for uniform distribution of Fe/Mo on silica support. Ethylsilicate-40 (CAS Registry No. 18954-71-7) was used as a silica source for the first time because of its higher silica content as well as low cost as compared to tetraethyl orthosilicate, which is generally preferred silica source for sol-gel synthesis of silica support in catalysis [15]. $250 \mathrm{~g}$ of ethylsilicate- 40 was mixed with $250 \mathrm{ml}$ of dry isopropyl alcohol under constant stirring. $5.225 \mathrm{~g}$ of ferric nitrate was dissolved in $100 \mathrm{ml}$ of isopropyl alcohol and was added to ethyl silicate solution under vigorous stirring. $20.31 \mathrm{~g}$ of ammonium heptamolybdate was dissolved in $100 \mathrm{ml}$ of water and was added to the above solution under constant stirring.

A viscous gel was obtained which was further stirred for another two hours and was kept overnight. A transparent solid product was obtained which was air dried and heated in an oven at $110^{\circ} \mathrm{C}$ for 12 hours. The product was further calcined at $450^{\circ} \mathrm{C}$ for 12 hours. The product was ground to fine powder, pressed in the form of pellet and granulated by crushing the pellet to -10 to +20 mesh size for use as a catalyst for reaction. The catalyst had the following composition.

$$
0.2 \mathrm{MoO}_{3}: 0.01 \mathrm{Fe}_{2} \mathrm{O}_{3}: 0.79 \mathrm{SiO}_{2}
$$

\subsection{2 $\mathrm{Mo} / \mathrm{SiO}_{2} \& \mathrm{Fe} / \mathrm{SiO}_{2}$ :}

The $15 \% \mathrm{Mo} / \mathrm{SiO}_{2}$ and $\mathrm{Fe} / \mathrm{SiO}_{2}$ catalysts were similarly prepared by using ammonium molybdate and ferric nitrate respectively with ethyl silicate- 40 as a silica source in the catalyst.

\section{2 Catalysts Characterization}

The catalysts were characterized by using XRD (Rigaku MiniFlex), SEM (Model JEOL JSM 5200), FT-IR (Nicolet 60, SX B), Thermal analysis (METTLER TA 4000 System), EDX (Kevex system), TPD of $\mathrm{NH}_{3}$ (Micrometrics, Autochem-2910) and surface area (Omnisorb 100 CX, COULTIER corp., USA).

\subsection{Reaction Procedure}

Vapor phase nitration was carried out by using a down-flow glass reactor with a fixed catalyst bed at an atmospheric pressure. $10 \mathrm{~g}$ of granulated catalyst was loaded in tubular glass reactor of $15 \mathrm{~mm}$ diameter and $25 \mathrm{~mm}$ length. The upper part of the reactor was packed with inert ceramic beads as preheating zone. The glass reactor was fixed inside the heater and reaction temperature was controlled by the thermocouple inserted in the catalyst bed.

Diluted nitric acid (30\%) and benzene were introduced into the flow reactor (Sage feed pumps) with nitrogen as a carrier gas. The product was condensed at $5^{\circ} \mathrm{C}$ and collected in a receiver. The reaction product was extracted with diethyl ether, which was analyzed by gas chromatography using GC (HP 6890, column: HP$1,30 \mathrm{~m}, 0.25 \mathrm{~mm}$ ID), GC/MS (SHIMADZU, column, DB-I).

\section{1 Catalyst Characterization}

\section{Results and Discussion}

\section{1. 1 X-ray Diffraction:}

The X-ray diffraction (XRD) patterns of the sample were recorded to ascertain the phase purity of the sample. The XRD pattern of $\mathrm{Fe} / \mathrm{Mo} / \mathrm{SiO}_{2}$ matched well with the reported $\mathrm{MoO}_{3}$ pattern without any reflections of silica species indicating the dispersion of $\mathrm{MoO}_{3}$ on amorphous silica (Fig. 1). In case of $\mathrm{Mo} / \mathrm{SiO}_{2}$ with $\mathrm{Mo}$ content of 5-15 mol \%, the catalysts were found to be amorphous showing high dispersion of $\mathrm{MoO}_{3}$ on amorphous silica support and above $20 \% \mathrm{MoO}_{3}$, the highly dispersed $\mathrm{MoO}_{3}$ forms crystalline clusters visible in $\mathrm{XRD}$ pattern as reported earlier [16-18]. 


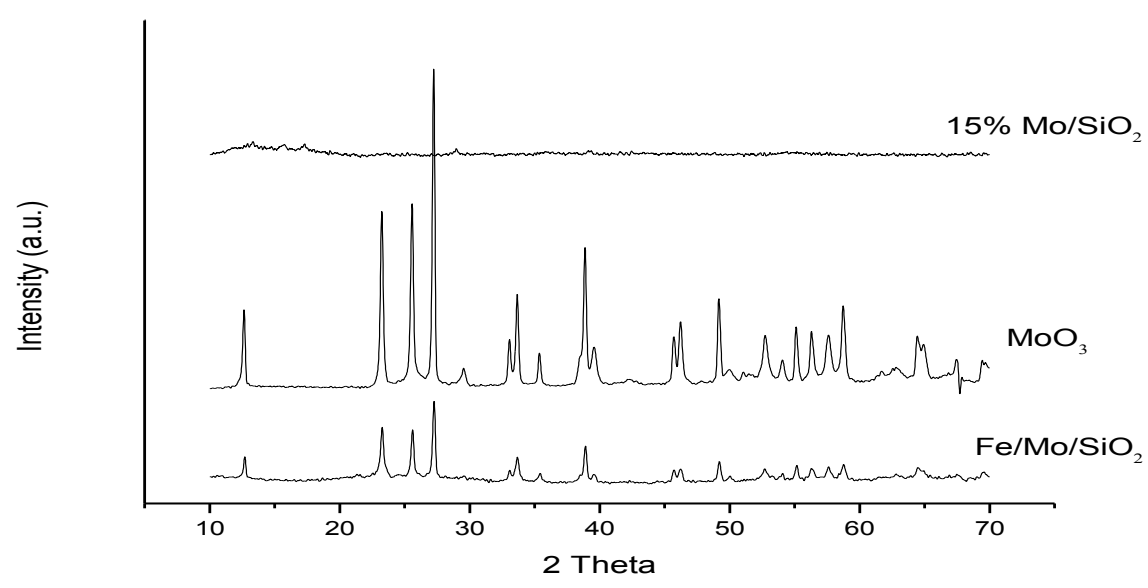

Fig. 1: $\mathrm{XRD}$ of $\mathrm{Fe} / \mathrm{Mo} / \mathrm{SiO}_{2}$ and $\mathrm{MoO}_{3}$

\section{1.2 Thermal Analysis:}

The thermal stability of catalyst $\mathrm{Fe} / \mathrm{Mo} / \mathrm{SiO}_{2}$ was tested using TG/DTA/DTG analysis. It showed that thermal stability of the catalyst upto $700{ }^{\circ} \mathrm{C}$.

\subsubsection{FTIR spectra of chemisorbed pyridine:}

FTIR spectra of chemisorbed pyridine at temperature 100 and $200{ }^{\circ} \mathrm{C}$ are showed in Fig. 2. In spectra observed with two bands at 1450 and $1610 \mathrm{~cm}^{-1}$ were observed which are due to co-ordinatively bonded

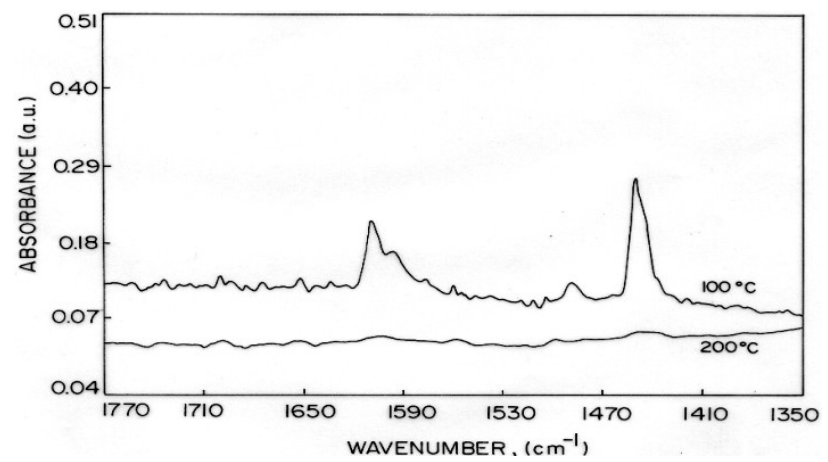

Fig. 2: IR of chemisorbed pyridine of $\mathrm{Fe} / \mathrm{Mi} / \mathrm{SiO}_{2}$.

pyridine to the surface, i.e. due to Lewis acid sites [19]. The bands observed at 1630 and $1540 \mathrm{~cm}^{-1}$ is due to pyridinium ion formed on Brönsted acid sites (which is very weak and negligible). The intensity of band due to Lewis acidity was measured at $100^{\circ} \mathrm{C}$ was very high, almost six times that observed at $200{ }^{\circ} \mathrm{C}$. It shows that Lewis acidity in $\mathrm{Fe} / \mathrm{Mo} / \mathrm{SiO}_{2}$ is also weak in nature.

\section{1. 4 SEM Analysis:}
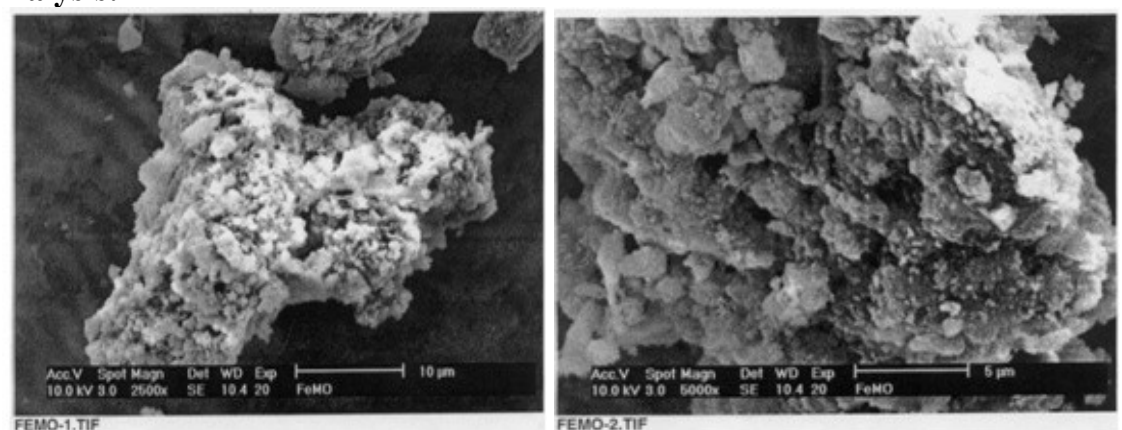

Fig. 3: Scanning electron micrograph of $\mathrm{Fe} / \mathrm{Mo} / \mathrm{SiO}_{2}$. 
Scanning electron micrograph of $\mathrm{Fe} / \mathrm{Mo} / \mathrm{SiO}_{2}$ is presented in the Fig. 3. The micrograph reveals agglomerates of small particles in the range of 0.1-0.3 $\mu \mathrm{m}$.

\subsubsection{Surface Area measurement:}

The surface area of the sample was calculated by the BET method [20], is given in the Table 1.

Table 1: Surface area of the catalysts

\begin{tabular}{l|c}
\hline & Surface area, $\mathrm{m}^{2} / \mathrm{g}$ \\
\hline $\mathrm{Fe} / \mathrm{Mo} / \mathrm{SiO}_{2}$ & 490.7 \\
$\mathrm{Mo} / \mathrm{SiO}_{2}$ & 496 \\
\hline
\end{tabular}

The values show that H-beta is free from occluded impurities. The high surface area of supported $\mathrm{Fe} / \mathrm{Mo}$ catalyst indicates that fine dispersion of $\mathrm{Fe}$ and $\mathrm{MoO}_{3}$ on silica support.

\section{1. 6 Temperature-programmed desorption (TPD) of ammonia:}

Temperature-programmed desorption (TPD) of ammonia is a common method for investigating both the strength and the number of acid sites present on the surface of a solid acid catalysts [20]. TPD of $\mathrm{Fe} / \mathrm{Mo} / \mathrm{SiO}_{2}, \mathrm{H}$-beta and $\mathrm{Mo} / \mathrm{SiO}_{2}$ are given below in Fig. 4. In Fe/Mo/SiO 2 catalyst ammonia desorption was about $1.22 \mathrm{mmolg}^{-1}$. TPD curve shows that mostly adsorbed $\mathrm{NH}_{3}$ is desorbed below $300^{\circ} \mathrm{C}$.

In case of H-Beta, ammonia desorption was about $0.78 \mathrm{mmol} \mathrm{g}^{-1}$, which is desorbed at higher temperature, indicating that it is having stronger acid sites than $\mathrm{Fe} / \mathrm{Mo} / \mathrm{SiO}_{2}$. TPD of $\mathrm{Mo} / \mathrm{SiO}_{2}$ showed about $1.10 \mathrm{mmolg}^{-1}$ was desorbed. The temperature of desorption is identical to $\mathrm{Fe} / \mathrm{Mo} / \mathrm{SiO}_{2}$. The addition of $\mathrm{Fe}$ to $\mathrm{Mo} / \mathrm{SiO}_{2}$ catalyst does not seem to have changed the nature of acidity significantly. Comparison of acidity of $\mathrm{H}-$ beta, $\mathrm{Mo} / \mathrm{SiO}_{2}$ and $\mathrm{Fe} / \mathrm{Mo} / \mathrm{SiO}_{2}$ showed that the $\mathrm{Fe} / \mathrm{Mo} / \mathrm{SiO}_{2}$ is having more acidity compared to others.

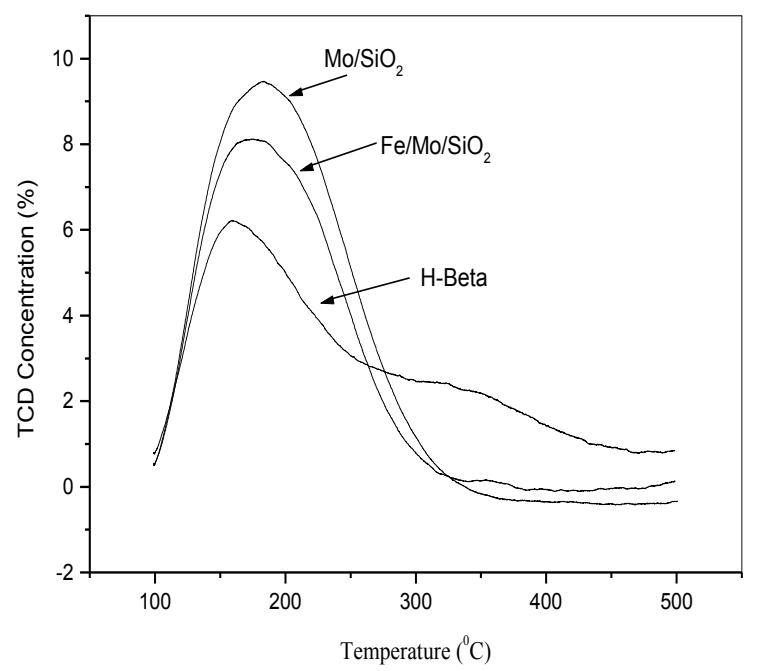

Fig. 4: TPD of ammonia of H-beta, $\mathrm{Fe} / \mathrm{Mo} / \mathrm{SiO}_{2}$ and $\mathrm{Mo} / \mathrm{SiO}_{2}$ catalysts.

\section{2 Reaction Study}

\section{2. 1 Investigation of active catalysts for nitration of benzene:}

Nitrobenzene is the main product in the nitration of benzene by nitric acid. The nitration of benzene is an exothermic reaction $(\Delta \mathrm{H}=-117 \mathrm{~kJ} / \mathrm{mol})$, therefore the heat of reaction during vapor phase nitration needs to be removed to maintain the reaction temperature in the range of 100 to $200{ }^{\circ} \mathrm{C}$. Use of dilute nitric acid would be an advantageous because heat is removed by steam generated from dilute nitric acid. It is also useful for generation of $\mathrm{NO}_{2}{ }^{+}$ion where as concentrated nitric acid produces nitrous oxide leading to low conversion of benzene to nitrobenzene. Considering these aspects benzene nitration was carried out using dilute nitric acid.

For comparison nitration of benzene was also carried out over various other solid acid catalysts using dilute nitric acid $(30 \%)$ at temperature $200{ }^{\circ} \mathrm{C}$ shown in Fig. 5. Among these catalysts investigated, the mixed oxide catalyst comprising $\mathrm{Fe} / \mathrm{Mo} / \mathrm{SiO}_{2}$ ( $\mathrm{I}, \mathrm{Fe}=0.72 \& \mathrm{Mo}=20 \mathrm{~mol} \%$ ) showed good yield of nitrobenzene with almost no decay of activity for $300 \mathrm{~h}$. Other solid acid catalysts such as $\mathrm{Mo} / \mathrm{SiO}_{2}(\mathrm{Mo}=20 \mathrm{~mol} \%), \mathrm{MoO}_{3}$, and various compositions of $\mathrm{Fe} / \mathrm{Mo} / \mathrm{SiO}_{2}(\mathrm{Fe} / \mathrm{Mo}=12 / 8 \mathrm{~mol} \mathrm{\% ,10/10} \mathrm{mol} \mathrm{\% )} \mathrm{showed} \mathrm{less} \mathrm{conversion} \mathrm{and} \mathrm{activity}$ of the catalysts and conversion was decreased with time on stream. $\mathrm{Fe} / \mathrm{Mo} / \mathrm{SiO}_{2}$ (I) was found to be active and 
having longer catalyst life. This may be due to the promotional effect of iron on the catalyst $\mathrm{Fe} / \mathrm{Mo} / \mathrm{SiO}_{2}$ (I) $[13,15]$. Comparison of activity of $\mathrm{Fe} / \mathrm{Mo} / \mathrm{SiO}_{2}$ (I) catalyst with that of other compositions of $\mathrm{Fe} / \mathrm{Mo} / \mathrm{SiO}_{2}$ catalysts shows that by increasing the amount of iron the conversion decreased as shown in Fig. 6. It indicates that small percentage of iron in $\mathrm{Fe} / \mathrm{Mo} / \mathrm{SiO}_{2}$ catalyst is significantly effective for the benzene nitration.

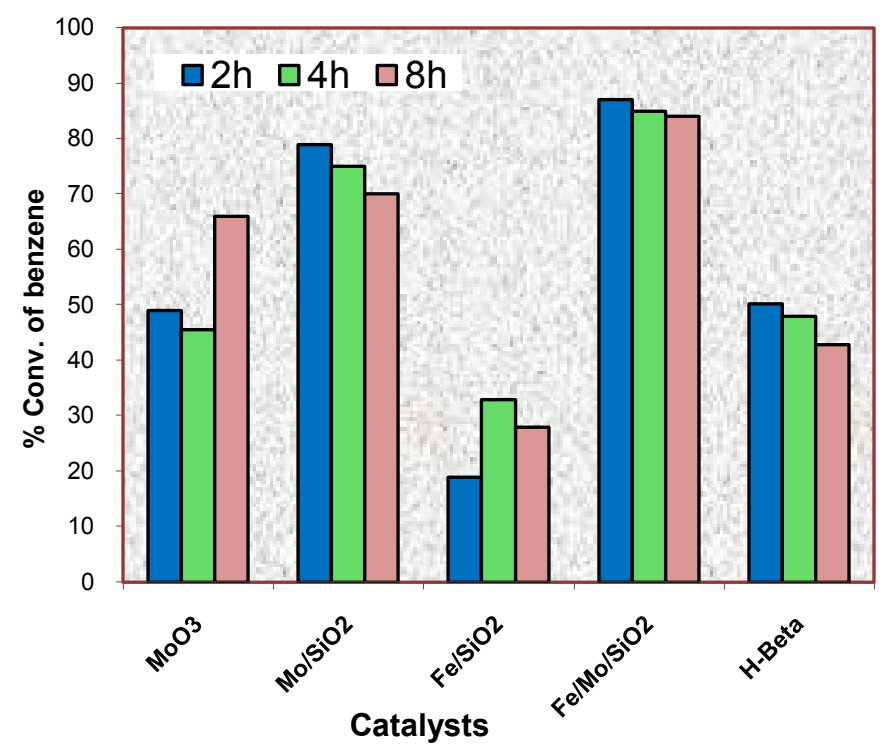

Fig. 5: Influence of various solid acid catalysts.

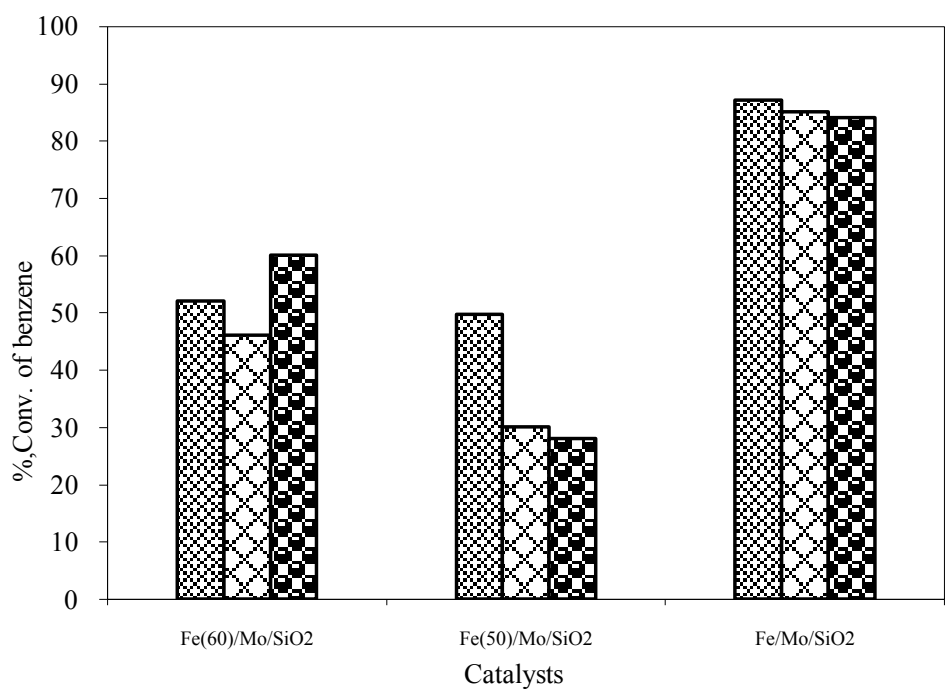

$\mathrm{Fe}(60) / \mathrm{Mo} / \mathrm{SiO}_{2}=\mathrm{Fe} / \mathrm{Mo}=12 / 8 ; \mathrm{Fe}(50) / \mathrm{Mo} / \mathrm{SiO}_{2}=\mathrm{Fe} / \mathrm{Mo}=10 / 10$; $\mathrm{Fe} / \mathrm{Mo} / \mathrm{SiO}_{2}=\mathrm{Fe} / \mathrm{Mo}=0.72 / 20$

Fig. 6: Comparison of $\mathrm{Fe} / \mathrm{Mo} / \mathrm{SiO}_{2}$ catalyst with different composition. 


\subsubsection{Effect of Temperature:}

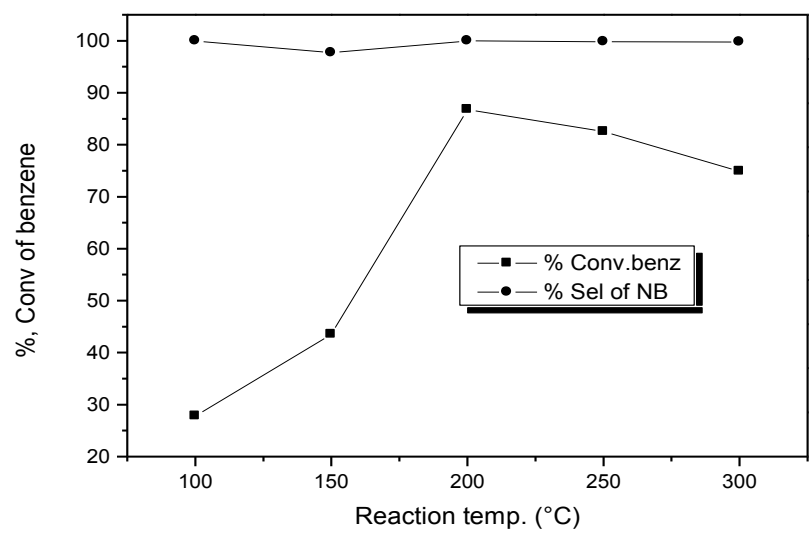

Fig. 7: Effect of temperature over $\mathrm{Fe} / \mathrm{Mo} / \mathrm{SiO}_{2}$ catalyst.

As the temperature increased from $100^{\circ} \mathrm{C}$ to $300^{\circ} \mathrm{C}$, the conversion increases and after temperature $200^{\circ} \mathrm{C}$ it start decreasing with formation of dinitro and other unidentified products in traces. The results of nitration of benzene over $\mathrm{Fe} / \mathrm{Mo} / \mathrm{SiO}_{2}$ using dilute nitric acid (30\%) as a nitrating agent at weight hourly space velocity (WHSV) $0.087 \mathrm{~h}^{-1}$ at nitric acid to benzene molar ratio 1.2 were shown in Fig. 7. It showed that at 200 ${ }^{\circ} \mathrm{C}$ the conversion and selectivity were higher with no other byproducts, but at $250{ }^{\circ} \mathrm{C}$ it showed low conversion for nitrobenzene and formation of dinitrobenzene in traces. As temperature increased there may be less formation of nitronium ion and more formation of nitrous oxide decreasing the formation of nitrobenzene [20]. The catalyst $\mathrm{Fe} / \mathrm{Mo} / \mathrm{SiO}_{2}$ exhibits dual function i.e. the formation of nitro product below $370^{\circ} \mathrm{C}$ and other is the formation of oxidation product above $400^{\circ} \mathrm{C}[15]$.

\section{2.3 Influence of Nitric acid to Benzene Molar Ratio:}

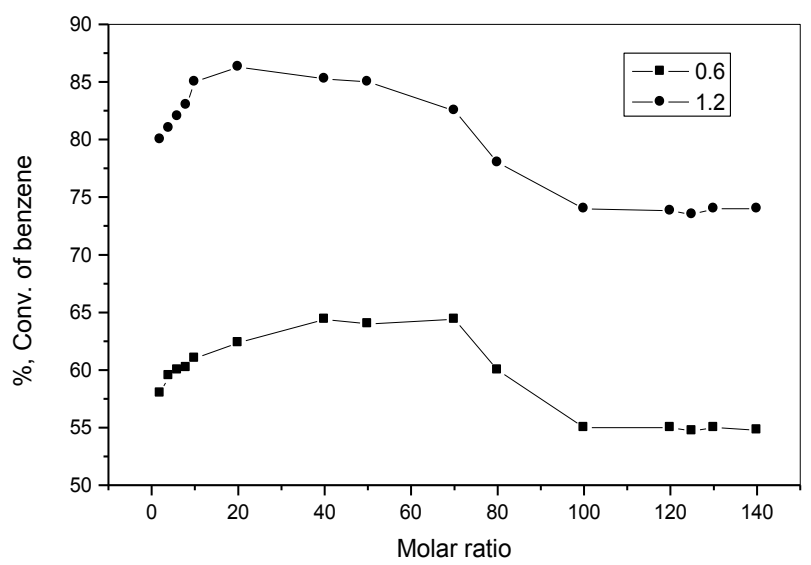

Fig. 8: Influence of molar ratio

The influence of the $\mathrm{HNO}_{3}$ /benzene molar ratio at temperature $200^{\circ} \mathrm{C}$ was examined over $\mathrm{Fe} / \mathrm{Mo} / \mathrm{SiO}_{2}$ (I) catalyst with time on stream. In the Fig. 8 variation of conversion of benzene with time on stream of reaction for nitric acid to benzene ratio of 0.6 and 1.2 are presented. After initial increasing conversion, it decreases further on time on stream and later it remains almost constant as can be seen in the Fig. 8. As nitric acid/ benzene ratio decreased the conversion also decreased. In the case of higher nitric acid to benzene molar ratio, as the available nitric acid was more, the conversion was also comparatively more. Dinitro formation was not observed below $200^{\circ} \mathrm{C}$ when $\mathrm{HNO}_{3} /$ Benzene ratio was 0.6 because of less than stoichiometric amount of $\mathrm{HNO}_{3}$ available. However at higher temperature and higher mole ratio of $\mathrm{HNO}_{3}$, dinitro product was also obtained in traces. 


\section{2.3 Effect of WHSV on Nitration of Benzene:}

The influence of WHSV on nitration of benzene at $200^{\circ} \mathrm{C}$ over catalyst $\mathrm{Fe} / \mathrm{Mo} / \mathrm{SiO}_{2}$ (I) using dilute nitric acid at nitric acid to benzene molar ratio 1.2 is presented in Fig. 9. An increase in WHSV decreases conversion, product yield and increases the oxidation and dinitro products. It showed that at lower WHSV $\left(0.087 \mathrm{~h}^{-1}\right)$ the conversion was higher $(86 \%)$ indicating that an optimum residence of reactants is required for maximum conversion.

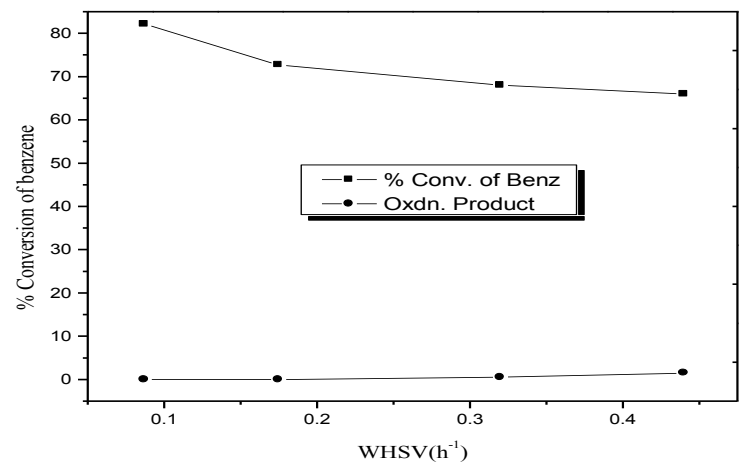

Fig. 9. Effect of WHSV.

\section{Conclusions}

Nitration of benzene (BZ) using dilute nitric acid (30\%) is promoted by solid acid catalysts $\mathrm{Fe} / \mathrm{Mo} / \mathrm{SiO}_{2}$ and related catalysts. Nitrobenzene was the major product and small amount of oxidation and dinitro products were formed. Among all catalysts studied, the $\mathrm{Fe} / \mathrm{Mo} / \mathrm{SiO}_{2}$ (I) catalyst gives higher conversion and selectivity for longer period of time (> $300 \mathrm{hrs})$.

One of the major advantages of this reaction was the use of dilute nitric acid as a nitrating agent, resulting in high selectivity and longer catalyst life. The use of sulfuric acid is avoided, which is essential in the conventional process. This process is avoiding hazardous waste disposal, which makes the process environmentally friendly.

\section{References}

[1]. R.L. Adkins, Nitrobenzene and Nitrotoluenes in Encyclopedia of Chemical Technology (Wiley-Interscience, New York 1996) $4^{\text {th }}$ edition, Vol. 17.

[2]. a) S. Suzuki, K. Tohmori, Y.Ono, Chem. Lett., 1986, 747

[3]. S. Suzuki, K. Tahmori, Y. Ono Y, Vapour phase nitration over poly-organo siloxanes bearing supho groups, Chem. Lett. 15, 1986, 747-750

[4]. L.E. Bertea, H.W. Kouwenhoven, R. Prins, Vapour-Phase Nitration of Benzene over Zeolitic Catalysts, Stud. Surf. Sci. Catal., 84, 1994, 1973.

[5]. L.E. Bertea, H.W. Kouwenhoven, R. Prins, Catalytic vapour-phase nitration of benzene over modified Y zeolites: influence of catalyst treatment, Stud. Surf. Sci. Catal., 78, 1993, 607.

[6]. V.V. Brei, S.V. Prudius, O.V. Melezhyk, Vapour-phase nitration of benzene over superacid $\mathrm{WO}_{3} / \mathrm{ZrO}_{2}$ catalysts, Appl. Catal. A, 239, 2003, 11-16.

[7]. N. S. Chaubal, M.R. Sawant, Vapor phase nitration of toluene over $\mathrm{CuFe}_{0.8}$, Catal. Commun. 8, 2007, 845-849.

[8]. S.M. Kemdeoa, V.S. Sapkalb, G.N. Chaudharia, $\mathrm{TiO}_{2}-\mathrm{SiO}_{2}$ mixed oxide supported MoO catalyst: Physicochemical characterization and activities in nitration of phenol, J. Mol. Catal. A, 323, 2010, 70-77.

[9]. T. Mishra, Anion supported $\mathrm{TiO}_{2}-\mathrm{ZrO}_{2}$ nanomaterial synthesized by reverse microemulsion technique as an efficient catalyst for solvent free nitration of halobenzene, Catal. Commun., 9, 2008, 21-26.

[10]. M. A. Zolfigol, B.F. Mirjalili, A. Bamoniri, M.A.K. Zarchi, A. Zarei, L. Khazdooz, J. Noei, Nitration of aromatic compounds on silica sulfuric acid, Bulletin of the Korean Chemical Society 25: 9, 2004, 1414-1416.

[11]. H. Sato, K. Hirose, K. Nagai, H. Yoshioka, Y. Nagaoka, Vapor phase nitration of benzene over solid acid catalysts II. Nitration with nitric acid (1); montmorillonite and mixed metal oxide catalysts, Appl. Catal. A: General, 175, 1998, 201.

[12]. H. Sato, K. Nagai, H. Yoshioka, Y. Nagaoka, Vapor phase nitration of benzene over solid acid catalysts IV. Nitration with nitric acid (3); supported sulfuric acid catalyst with co-feeding of a trace amount of sulfuric acid, Appl. Catal. A: General, 180, $1999,359$.

[13]. Gong Shu-wen, Liu Li-jun, Zhang Qian, Wang Liang-yin, Effective Liquid-phase Nitration of Benzene Catalyzed by a Stable Solid Acid Catalyst: Silica Supported $\mathrm{Cs}_{2.5} \mathrm{H}_{0.5} \mathrm{PMo}_{12} \mathrm{O}_{40}$, Bull. Korean Chem. Soc., 33(4), 2012, 1279-1284.

[14]. J.S. Yoo, A.R. Sohail, S.S. Grimmer, J.Z. Shyu, One-step hydroxylation of benzene to phenol i. gas-phase nitric acid oxidation over $\mathrm{Fe} / \mathrm{Mo} / \mathrm{SiO}_{2}$, Appl Catal. A: General, 117, 1994, 1-16.

[15]. D.P. Sabde, S.G. Hegde, M.K. Dongare, Synthesis of titanium silicate-1 using ethyl silicate-40: a new source for zeolite synthesis, J. Mater. Chem., 10(6), 2000, 1365.

[16]. L. Lietti, G. Ramis, G. Busca, P. Forzatti and F. Bregani, Characterization and reactivity of $\mathrm{MoO}_{3} / \mathrm{SiO}_{2} \mathrm{De}-\mathrm{NOx}_{\mathrm{x}}$ catalysts in the selective catalytic oxidation of ammonia to $\mathrm{N}_{2}$, Catal. Today, 61, 2000, 187-195.

[17]. J.J.P. Biermann, F.J.J.G. Janssen, J.W. Geus, Molybdena on silica catalysts: selective catalytic oxidation of ammonia to nitrogen over MoO3 on $\mathrm{SiO} 2$ catalysts, J. Mol. Catal. 60, 1990, 229-238. 
[18]. C. Jia, P. Massiani, D. Barthomeuf, Characterization by infrared and nuclear magnetic resonance spectroscopies of calcined beta zeolite, J. Chem. Soc., Faraday Trans., 89 (19), 1993, 3659-3665.

[19]. K. Parida, V. Quaschning, E. Lieske, E. Kemnitz, Freeze-dried promoted and unpromoted sulphated zirconia and its Application in catalysis, J. Mater. Chem., 11, 2001, 1903-1911.

[20]. L.V. Malysheva, E.A. Paukshtis, K.G. Ione, Nitration of Aromatics by Nitrogen Oxides on Zeolite Catalysts: Comparison of Reaction in the Gas Phase and Solutions. Catal. Rev. Sci. Eng. 37, 1995, 179-226. 